\title{
Workplace Bullying in Private Companies in the Philippines: Major Cause of Employee Burnout
}

\author{
Kenneth L. Armas, Clarizza L. De Leon, Angelo R. Santos and Edgelly G. Vitug
}

College of Management and Business Technology, NEUST, Philippines

\begin{abstract}
This study was conducted to determine the existence of workplace bullying in private companies in the Philippines as major cause of employee burnout. The study utilized descriptive method of research having 100 respondents from different private companies. Respondents are equally divided into female and male. Structured questionnaire was the main instrument of the study during the survey conducted.

Most of the respondents interviewed were between 18 to 22 years old. There were 4 variables considered in describing how may bullying evaluated in terms of; injustice, destructive behavior, obstruction to achieve work target and work autonomy. The majority of the male respondents are saying that the bullying inside the workplace was particularly happens when someone's using abusive language. On the other hand, most of the female respondents are saying that it happens when unreasonable work load is given. The majority of the male respondents are saying that the destructive behavior inside the workplace happens when they are the repeatedly target of superior's ire while most of the female respondents are saying that it happens when they are the repeatedly target of superior's ire and if they are threatened to remove from work. The majority of the male and female respondents are saying that the obstruction to achieve work target will prevent if reasonable work is given. The majority of the male and female respondents are saying that the work autonomy happens if the job will be performing with atleast supervision.
\end{abstract}

There is a significant relationship between the age of the respondent and their evaluated experiences in bullying. Significant relationship between the sex of the respondent and their evaluated experiences in bullying. The possible programs \& policies for companies to solve the existing bullying in the workplace.

Keywords-employee burnout, employee welfare, private companies in the Philippines, workplace bullying.

\section{INTRODUCTION}

Life is an odd mixture of different moments of action and inaction, work and rest.(Harees, 2012)Business Dictionary defined work is a job and as something that should be done to earn money. Work means saving the person from the dullness and boredom of life. It puts our energies to a proper use. Unuseenergies create disorders in us. Consequently, Work can make people physically unhealthy and mentaly unhappy. Indeed, work can provides us with money for livelihood, part of it is use to sustain our daily basic needs in life for ourfamily and education; furthermore, it can help us to contribute in our community itself.(Harees, 2012)

Violence is a form of storm causes great fear to others. Business Dictionary defined violence as a physical force unlawfully exercised toward property or persons, causing damage or injury. Hence,many Filipinos face bullying at work.(Bullying, 2016) Although workplace bullying is not a popular topic of conversation, it is quite rampant in countries all over the world. (The World's Authority on Bullying, 2015)

According to Workplace bullying institute, Workplace Bullying consist of three basic types of abuse emotional, verbal and physical.It typically involved subtitle methods of coercion such as threatening, humiliating, or work intimidating, work interference, sabotage which prevents work from getting done, or abuse. However, Workplace bullying can be defined in many different ways. According to the (Workplace Bullying Institute, 2016) "The victim of bullying is sometimes referred to as a target"

Several studies indicate that Office bullying or Workplace bullying is similar to School bullying but not the same.In some cases, it is called Workplace harassment, some countries bullying incidents are referred to minors and harassment to adults. In the Philippines we use bullying for both minors and adults. (Santos, 2014)Therefore, any form of harassment or abuse, in the workplace, may negatively impact to the mental and physical health of an employee.(Einarsen, Hoel,Notelaers, 2009) 
In 2013, President Aquino Benigno S. $3^{\text {rd }}$ signed into Law Republic Act No. 10627, or the Anti Bullying Act of 2013. Thus, the Law mandates all elementary and secondary schools and learning centers in the Philippines to adopt Anti-Bullying Policy. However, Bullying does not end when one graduates from school. Bullying exist in the workplace and there is no current law to address that matter. The closest to it that have present is House Bill No. 815, or the Anti Bullying Act of 2016, which was filed in the House of Representative by RodelBatocabe and Christopher Co of Partylist Group. "Ako Bicol" in the 17th Congress.

Even though there is no universally accepted definition of workplace bullying, the researchers aim to explore the effects of workplace bullying in selected companies in Nueva Ecija. Therefore, one of the main objectives of this study is to give the business firms an idea on how to avoid this type of situation in order to have an effective and efficient working environment.

Based on the content mentioned above, these are the reasons of the researchers to conduct this study. The said study may bring significant impact to the companies for them to formulate programs that will protect their workers from bullying.

\subsection{Literature Survey Workplace bullying}

Work is a defining factor in a person's life, identity, and well being. Therefore, some researchers have indicated that the experience of being bullied at work has devastating immediate and long-term consequences, especially for the victims or targets of this behavior (Roscigno, Lopez,\&Hodson, 2009) Moreover, several studies have shown that negative emotions, psychological symptoms, commonly result from bullying at work, and target's emotional injuries typically persist long after the bullying experiences has ended (Einarsen, Hoel, \&Notelaers, 2009; Roscigno, Lopez, Hodson, 2009)

While,there is no single universally accepted definition of workplace bullying,there is a general agreement among researchers that this phenomenon is an experience of repeated and persistent negative acts toward one or more individuals, in a work-related environment. (Lewis,Sheehan,\& Davies, 2008; Einarsen, Hoel, Notelaers, 2009; Roscigno, Lopez, \&Hodson, 2009)

\section{Workplace Bullying has two main categories:}

Researchers indicate stated that workplace bullying has two main categories which are shape upon. One of these categories is work-related bullying, which are unwanted repeated actions and practices that are directed to one or more workers. (Wilkes,\& Vickers 2008) It may cause humiliation, distress, and that may interfere with work performance and create an unpleasant working environment. Work-related bullying behaviors may include an unachievable task, impossible deadlines, unmanageable workloads, meaningless task or supplying unclear information, threat about security etc. (Hutchinson et al.,2008)

The Other category is person-related bullying which is regarded as a form of stress that is capable of causing negative effects on employees health, probably leads to psychological symptoms, psychiatric trouble such as anxiety-depression disorders, chronic adjustment disorder and post-traumatic stress disorder. Person-related bullying behaviors are ignoring, insulting public humiliation, spreading rumors or gossips, and intruding on privacy,yelling etc. (Ramsay T. B., 2010)

\section{Causes and effects of Workplace Bullying}

These bullying experiences usually occur over prolonged periods of time and include behaviors such as constant criticism, gossip, blaming, and social exclusion, to name a few (Roscigno, Lopez, \&Hodson, 2009; OlenderRusso, 2009). Interestingly, as with many forms of workplace aggression, bullying may begin as psychological harassment but ultimately escalate into physical acts of violence or abuse.

Several researchers have indicated that workplace bullying typically involves a perceived power imbalance, and that this behavior often ultimately results in a harmful and unhealthy work environment (Lewis, Sheehan,\& Davies,2008;Roscigno,Lopez,\& Hodson,2009). In fact, Some studies have also demonstrated that, in most cases, the target of bullying is a relatively powerless worker who often lacks the resources or ability to defend oneself (OlenderRusso,2009) For instance, incidents of bullying have been shown to decrease the morale, productivity and general work-quality of the bullied and non-bullied workers, within an organization (Roscigno, 2009)This negative behavior is also capable of significantly impacting the overall success of an organization due to factors such as high rates of employee absenteeism and turn over(Lewis,Sheehan,\& Davies,2008; Baillien, Neyens, De Witte,\& De Cuyper,2009). Indeed, studies have shown that bullying is a common reas on for why some workers leave jobs, especially within their first year of employment, thereby significantly increasing the costs of employment, increasing the costs of organizational 
recruiting, hiring and training (Simons, 2008;Lewis, Sheehan,\& Davies, 2008; Olender-Russo, 2009).

\section{Further Literature Review}

Similar to the literature, Wiedmer (2011) defines workplace bullying as repetitive negative behavior to one or more persons. Examples of workplace bullying are: verbal abuse, offensive conduct which can be perceived as threatening or hostile, and actions which prevent an employee from completing their work.

However, Survey research indicates that workplace bullying is a predictor for anxiety and depression as well as job dissatisfaction, turnover and absenteeism. Results indicate that those individuals who were bullied may also become bullies themselves. Situational factors such as work conflicts also resulted in bullying behavior. (Hauge, Skogstad; \& Einarsen 2010)

Some Researchers recommend that management develop anti-bullying policies. (Glaso, Matthiesen, Nielsen\&Einarsen 2010) focused on whether there was a typical personality profile for bullied employees. Their research indicates that those individuals who were more likely to be bullied were characterized as more anxious and neurotic, less extroverted, less organized and less dependable.(De Cuyper, Baillen\& De Witte 2009) survey research examined the relationship between the job stressor, job insecurity, and workplace bullying. Hence, Some Research in the field of workplace bullying has mainly focused on psychological and behavioral perspective. The causes to why people bully others and outcomes for the ones exposed to the bullying-like stress or work efficacy-have been explored. (Berry et al, 2012).

\subsection{Objectives of the Study}

This study was conducted to determine the existence of workplace bullying in private companies in District IV of Nueva Ecija. Specifically, the study has the following objectives:
1. Describe the respondents' profile in terms of age and sex.

2. Determine the existing forms of bullying in terms of:

a. Injustices;

b. Destructive behavior;

c. Obstruction to achieve work target; and d. Work autonomy.

3. Determine if there is significant relationship between the age of the respondents and their evaluated experiences in bullying.

4. Determine if there is significant relationship between the sex of the respondents and their evaluated experiences in bullying.

5. Identify the possible programs and policies for companies to solve the existing bullying.

\subsection{Hypotheses}

Ho: 1. There is no significant relationship between the age of the respondents and their evaluated experiences.

Ho: 2. There is no significant relationship between the sex of the respondents and their evaluated experiences.

\subsection{Method Used}

The study was a descriptive research in which the primary aimed was to describe the phenomena happening on selected private companies in District IV of Nueva Ecija. Descriptive method is the most appropriate method since it describes with emphasis what actually exist such as current conditions, practices situations, or any phenomena.

\subsection{Research Locale}

Municipalities in District IV of Nueva Ecija served as the location of the study. Specifically, municipalities of Jaen, San Isidro, San Antonio, Cabiao, San Leonardo, Gapan, Penaranda and Gen. Tinio. 


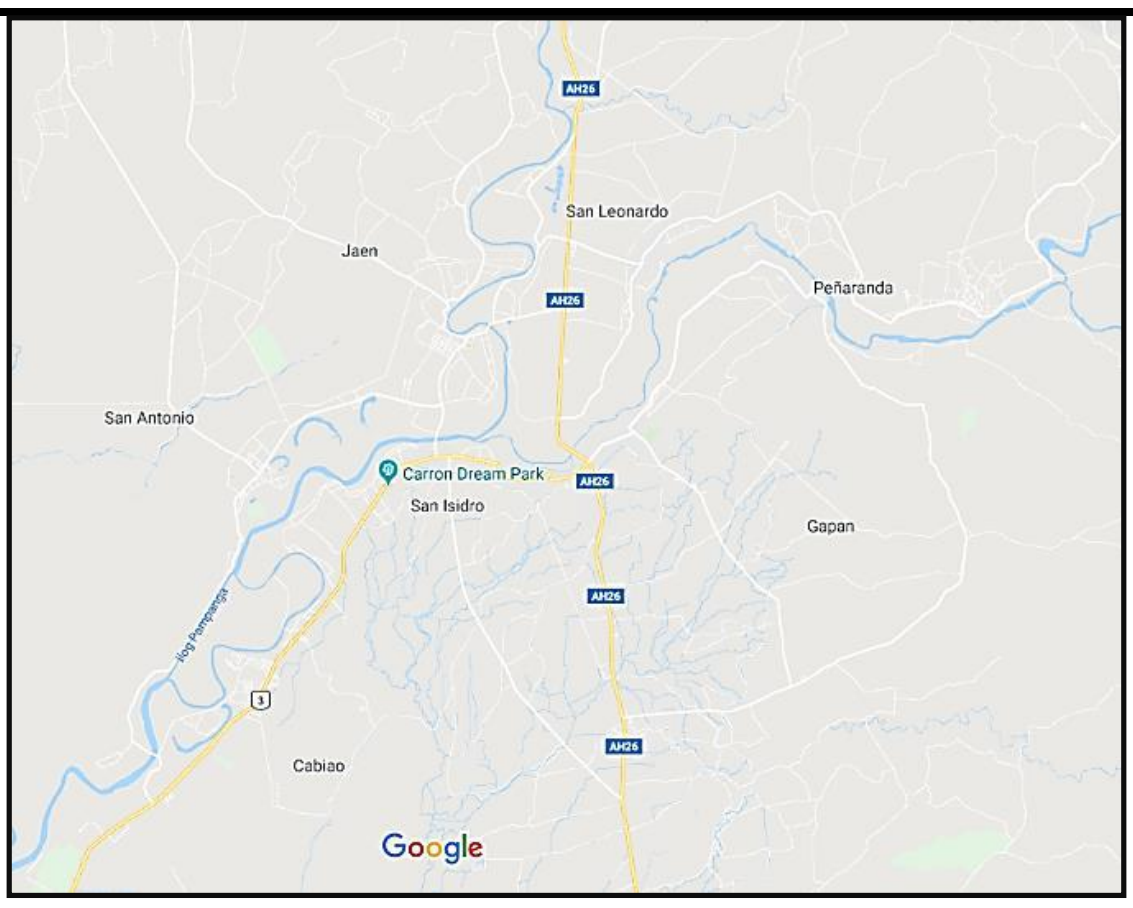

Fig.1: Location of the Study (District IV of Nueva Ecija)

\subsection{Respondents of the Study}

The respondents of this study came from the selected supermarkets in District IV of Nueva Ecija. The target respondents were 100 workers in District IV of Nueva Ecija. Respondents were equally divided in terms of age, 50 male and 50 female.

There were 10 private companies subjected in the study which the industry they belong was assumed to be irrelevant in the study. There were five (5) male and five (5) female respondents in each company participated in the study.

\subsection{Sampling Techniques}

The researchers used quota sampling in selecting the respondents of the study. This is the most appropriate method since the researchers were able to ensure equal or proportionate representational of subjects depending on which trait was considered as basis of the quota.

\subsection{Instrument of the Study}

The main instrument of the study was a structured questionnaire. Which the researchers were able to ensure the validity of the instrument so that it will measure what it intends to measure in accordance to the objectives of the study.

The step was conducted the intensive review of related literature and studies to familiarize the researchers on the main problem of the study. After the review of related literature and studies, the researchers was construct the instrument in accordance to the objectives of the study.

\subsection{Techniques in Gathering Data}

The researchers used techniques in gathering the needed data and it was in the form of survey, interview, focus group discussion and documents \& record collection. Statistical Treatment utilize frequency count and percentage.

Survey - composed of six parts, namely, injustice, destructive behavior, obstruction to achieve work target, and work autonomy.

Interview - this was conducted by the researcher in District IV of Nueva Ecija that has employees who are currently involve into workplace bullying.

Focus Group Discussion (FGD)- A focus group discussion (FGD) is a good way to gather together people from similar backgrounds or experiences to discuss a specific topic of interest. The group of participants is guided by a moderator (or group facilitator) who introduces topics for discussion and helps the group to participate in a lively and natural discussion among themselves.

Documents \& Record Collection - With the use of records and information from data, the researchers gathered factual data for creating the questionnaire.

\subsection{Data Analysis Tools}


The researchers used two (2) statistical tools to facilitate the ease analysis and interpretation of data. Frequency of distribution and percentile was used to describe the respondents of the respondents in their age and experience bullying in terms of injustices, obstructive behavior and work autonomy.

Furthermore, Kruskal-Wallis was used to determine the correlation of age and sex to experiences relating to workplace bullying of the respondents. This is a nonparametric tool can determine the relationship between identified variables if the total population was not stated and respondents were selected using non-probability sampling. Since the researchers were not able to determine the total population and respondents were selected using quota sampling (non-probability sampling).

\subsection{Demographic Profile of the Respondents}

\section{RESULTS AND DISCUSSION}

Table 1. Demographic Profile of the Respondents

\begin{tabular}{|c|c|c|c|c|}
\hline Demographic Profile & \multicolumn{2}{|c|}{ Male } & \multicolumn{2}{c|}{ Female } \\
\hline Age of the Respondents & Frequency & Percentage & Frequency & Percentage \\
\hline $18-22$ & & & & \\
\hline $23-27$ & 11 & $22 \%$ & 24 & $48 \%$ \\
\hline $28-32$ & 24 & $48 \%$ & 18 & $36 \%$ \\
\hline $33-37$ & 13 & $26 \%$ & 5 & $10 \%$ \\
\hline $38-42$ & 0 & $0 \%$ & 1 & $2 \%$ \\
\hline 43 and above & 1 & $2 \%$ & 0 & $0 \%$ \\
\hline Total & 1 & $2 \%$ & 2 & $4 \%$ \\
\hline Sex & 50 & $100 \%$ & 50 & $100 \%$ \\
\hline
\end{tabular}

Table 1 shows the demographic profile of the respondents. Out of 50 male respondents, 24 or $48 \%$ of them are $23-27$ years of age, and 0 or $0 \%$ of them are 33-37 years of age. On the other hand, out of 50 female respondents, 24 or $48 \%$ of them are $18-22$ years of age, and 0 or $0 \%$ of them are $38-42$ years of age.

\subsection{Experienced Workplace Bullying in the Workplace}

\subsubsection{Injustices}

\begin{tabular}{|c|c|c|c|c|c|c|c|c|c|c|c|c|}
\hline \multirow{3}{*}{ Injustice } & \multicolumn{6}{|c|}{ Yes } & \multicolumn{6}{|c|}{ No } \\
\hline & \multicolumn{2}{|c|}{ Male } & \multicolumn{2}{|c|}{ Female } & \multicolumn{2}{|c|}{ Total } & \multicolumn{2}{|c|}{ Male } & \multicolumn{2}{|c|}{ Female } & \multicolumn{2}{|c|}{ Total } \\
\hline & f & $\%$ & $\mathbf{f}$ & $\%$ & $\mathbf{F}$ & $\%$ & $\mathbf{f}$ & $\%$ & $\mathbf{f}$ & $\%$ & f & $\%$ \\
\hline $\begin{array}{l}\text { 2.Unreasonable work load } \\
\text { is given }\end{array}$ & 21 & $42 \%$ & 28 & $56 \%$ & 49 & $49 \%$ & 29 & $58 \%$ & 22 & $44 \%$ & 51 & $51 \%$ \\
\hline $\begin{array}{l}\text { 4.Excluded from } \\
\text { receiving benefits }\end{array}$ & 8 & $16 \%$ & 10 & $20 \%$ & 18 & $18 \%$ & 42 & $84 \%$ & 40 & $80 \%$ & 82 & $82 \%$ \\
\hline $\begin{array}{l}\text { 5.Treated with } \\
\text { intimidation }\end{array}$ & 16 & $32 \%$ & 18 & $36 \%$ & 34 & $34 \%$ & 34 & $68 \%$ & 32 & $64 \%$ & 66 & $66 \%$ \\
\hline
\end{tabular}

As can be gleaned on table 2 regarding Experienced Workplace Bullying in the Workplace "Injustices", The highest items who answered yes with 49 or $49 \%$ were 2 "Unreasonable work load is given" and 3 "Using abusive language", and the lowest item who answered yes with 18 or $18 \%$ was 4 "Excluded from receiving benefits". On the other hand, the highest item who answered no with 82 or $82 \%$ was 4 "Excluded from receiving benefits", and the lowest items who answered no with 51 or $51 \%$ were 2 "Unreasonable work load is given" and 3 "Using abusive language". 


\subsubsection{Destructive Behavior}

\begin{tabular}{|c|c|c|c|c|c|c|c|c|c|c|c|c|}
\hline \multirow{3}{*}{ Destructive Behaviour } & \multicolumn{6}{|c|}{ Yes } & \multicolumn{6}{|c|}{ No } \\
\hline & \multicolumn{2}{|c|}{ Male } & \multicolumn{2}{|c|}{ Female } & \multicolumn{2}{|c|}{ Total } & \multicolumn{2}{|c|}{ Male } & \multicolumn{2}{|c|}{ Female } & \multicolumn{2}{|c|}{ Total } \\
\hline & $f$ & $\%$ & $f$ & $\%$ & $F$ & $\%$ & $f$ & $\%$ & $f$ & $\%$ & $f$ & $\%$ \\
\hline $\begin{array}{l}\text { 1. Repeatedly the target of } \\
\text { superior's ire }\end{array}$ & 36 & $72 \%$ & 32 & $64 \%$ & 68 & $68 \%$ & 14 & $28 \%$ & 18 & $36 \%$ & 32 & $32 \%$ \\
\hline $\begin{array}{l}\text { 2. Repeatedly shouted upon by } \\
\text { my boss }\end{array}$ & 28 & $56 \%$ & 22 & $44 \%$ & 50 & $50 \%$ & 22 & $44 \%$ & 28 & $56 \%$ & 50 & $50 \%$ \\
\hline $\begin{array}{l}\text { 3. Harassed for unknown } \\
\text { reason }\end{array}$ & 17 & $34 \%$ & 21 & $42 \%$ & 38 & $38 \%$ & 33 & $66 \%$ & 29 & $58 \%$ & 62 & $62 \%$ \\
\hline $\begin{array}{l}\text { 4. Humiliation for slight } \\
\text { mistake committed }\end{array}$ & 27 & $54 \%$ & 28 & $56 \%$ & 55 & $55 \%$ & 23 & $46 \%$ & 22 & $44 \%$ & 45 & $45 \%$ \\
\hline $\begin{array}{l}\text { 5. Threatened to remove from } \\
\text { work }\end{array}$ & 34 & $68 \%$ & 32 & $64 \%$ & 66 & $66 \%$ & 16 & $32 \%$ & 18 & $36 \%$ & 34 & $34 \%$ \\
\hline
\end{tabular}

As can be seen on table 3 regarding Experienced Workplace Bullying in the Workplace "Obstructive behavior", The highest items who answered yes with 68 or $68 \%$ was 1 "Repeatedly the target of superior's ire", and the lowest item who answered yes with 38 or $38 \%$ was 3 "Harassed for unknown reason". On the other hand, the highest item who answered no with 62 or $62 \%$ was 3 "Harassed for unknown reason", and the lowest item who answered no with 32 or $32 \%$ was 1 ".Repeatedly the target of superior's ire".

\subsubsection{Obstruction to Work}

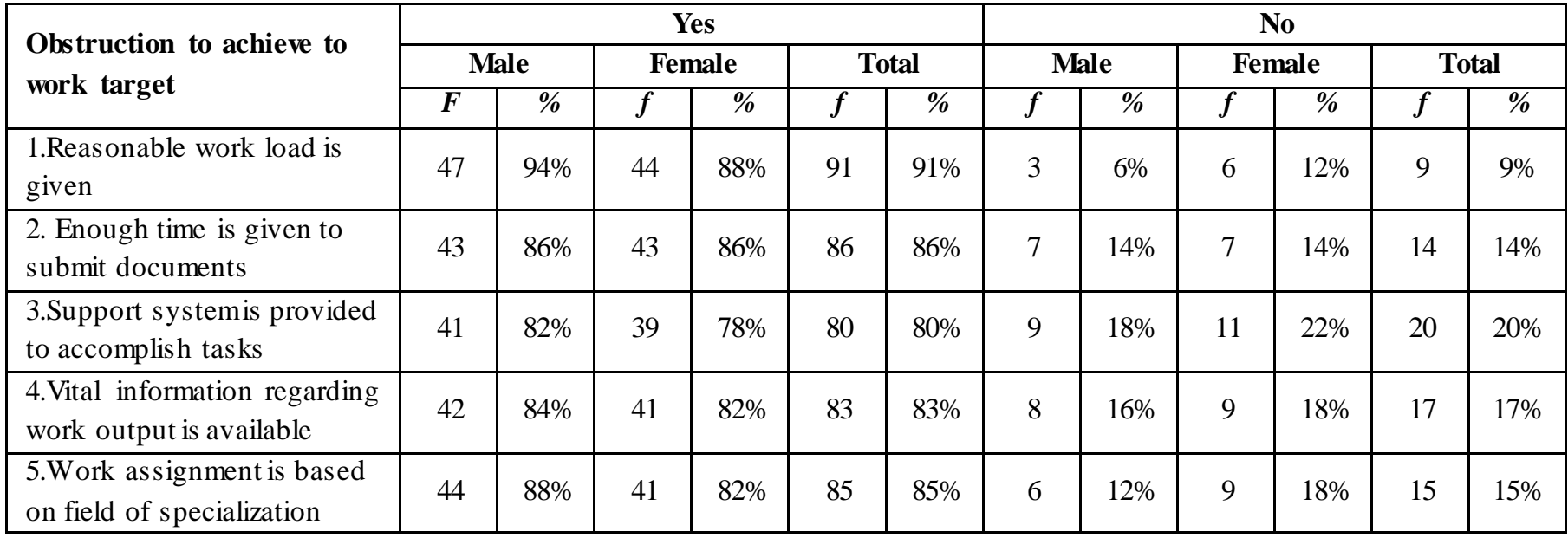

As can be shown on table 4 regarding Experienced Workplace Bullying in the Workplace "Obstruction to work", The highest items who answered yes with 91 or $91 \%$ was 1 "Reasonable work is given", and the lowest item who answered yes with 80 or $80 \%$ was 3 "Support System is provided to accomplish tasks". On the other hand, the highest item who answered no with 20 or $20 \%$ was 3 "Support System is provided to accomplish tasks", and the lowest item who answered no with 9 or $9 \%$ was 1 "Reasonable work is given".

\subsubsection{Work Autonomy}

\begin{tabular}{|c|c|c|c|c|c|c|c|c|c|c|c|c|}
\hline \multirow{3}{*}{ Work Autonomy } & \multicolumn{6}{|c|}{ Yes } & \multicolumn{6}{|c|}{ No } \\
\hline & \multicolumn{2}{|c|}{ Male } & \multicolumn{2}{|c|}{ Female } & \multicolumn{2}{|c|}{ Total } & \multicolumn{2}{|c|}{ Male } & \multicolumn{2}{|c|}{ Female } & \multicolumn{2}{|c|}{ Total } \\
\hline & $f$ & $\%$ & $f$ & $\%$ & $f$ & $\%$ & $\bar{f}$ & $\%$ & $f$ & $\%$ & $\bar{f}$ & $\%$ \\
\hline
\end{tabular}




\begin{tabular}{|l|c|c|c|c|c|c|c|c|c|c|c|c|}
\hline $\begin{array}{l}\text { 2.There is freedom to } \\
\text { determine work performance }\end{array}$ & 39 & $78 \%$ & 40 & $80 \%$ & 79 & $79 \%$ & 11 & $22 \%$ & 10 & $20 \%$ & 21 & $21 \%$ \\
\hline $\begin{array}{l}\text { 3.There is freedom to choose } \\
\text { how and when working } \\
\text { assignment is to be done }\end{array}$ & 41 & $82 \%$ & 37 & $74 \%$ & 78 & $78 \%$ & 9 & $18 \%$ & 13 & $26 \%$ & 22 & $22 \%$ \\
\hline $\begin{array}{l}4 . \text { Superior determines what to } \\
\text { teach to their employees }\end{array}$ & 44 & $88 \%$ & 43 & $86 \%$ & 87 & $87 \%$ & 6 & $12 \%$ & 7 & $14 \%$ & 13 & $13 \%$ \\
\hline $\begin{array}{l}\text { 5.My superior is output } \\
\text { oriented rather than procedure } \\
\text { oriented }\end{array}$ & 44 & $88 \%$ & 43 & $86 \%$ & 87 & $87 \%$ & 6 & $12 \%$ & 7 & $14 \%$ & 13 & $13 \%$ \\
\hline
\end{tabular}

As can be noticed on table 5 regarding Experienced Workplace Bullying in the Workplace "Work Autonomy", the highest items who answered yes with 93 or $93 \%$ was 1 "The job will be performing with atleast supervision", and the lowest item who answered yes with 78 or $78 \%$ was 3 "There is freedom to choose how and when working assignment is to be done". On the other hand, the highest item who answered no with 22 or $22 \%$ was 3 "There is freedom to choose how and when working assignment is to be done", and the lowest item who answered no with 7 or $7 \%$ was 1 "The job will be performing with atleast supervision".

\subsection{Relationship of Age to Experienced Workplace Bullying}

\begin{tabular}{|r|c|c|}
\hline \multicolumn{1}{|c|}{ Experiences } & Correlation & Verbal Interpretation \\
\hline 1. Injustice & & \\
\hline a. Promotion is based on merit & 0.09 & Weak positive Correlation \\
\hline b. Unreasonable work load is given. & 0.01 & Weak positive correlation \\
\hline c. Using abusive language & 0.17 & Weak negative correlation \\
\hline d. Excluded from receiving benefits. & 0.01 & Weak negative correlation \\
\hline e. Treated with intimidation. & 0.17 & Weak negative correlation \\
\hline 2. Destructive Behavior & & \\
\hline a. Repeatedly the target o superior's ire. & -0.03 & Weak negative correlation \\
\hline b. Repeatedly shouted upon by my boss. & 0.02 & Weak positive correlation \\
\hline c. Harassed for unknown reason. & -0.04 & Weak negative correlation \\
\hline d. Humiliation for slight mistake committed. & 0.01 & Weak positive correlation \\
\hline e. Threatened to remove from work. & 0.07 & Weak positive correlation \\
\hline 3. Obstructions to achieve work target & & \\
\hline a. Reasonable work load is given. & 0.14 & Weak positive correlation \\
\hline b. Enough time is given to submit documents. & -0.16 & Weak negative correlation \\
\hline c. Support system is provided to accomplish task's. & 0.06 & Weak positive correlation \\
\hline d. Vital information regarding work output is available. & -0.03 & Weak negative correlation \\
\hline e. Work assignment is based on filled of specialization. & -0.03 & Weak negative correlation \\
\hline 4. Work Autonomy & & \\
\hline a. The job will be performing with at least supervision. & -0.01 & Weak negative correlation \\
\hline b. There is freedom to determine work performance. & 0.02 & Weak positive correlation \\
\hline c. There is freedom to choose how and when working & 0.08 & Weak positive correlation \\
\hline assignment is to be done. & & Weak positive correlation \\
\hline e. Superior determine what to teach their employees. & 0.13 & Weak positive correlation \\
\hline$\quad$ oriented. & 0.09 & \\
\hline
\end{tabular}


Table 6 shows that Relationship of Age to Experienced Workplace Bullying in terms of injustice, destructive behavior, obstruction to achieve work target, and work autonomy had -0.01 to 0.17 correlation with the verbal interpretation of "Weak positive correlation".

\section{REFERENCES}

[1] De Lara, Marlon (2012). Effects of Bullying. Retrieve from

https://www.s lideshare.net/victorias antos 9822924/bull ying-thes is

[2] Batur, Martina and Wistrom, Emma (2012) Workplace Bullying, A Study about Awareness, Preparedness and Implementation, Retrieve from, https://gupea.ub.gu.se/bits tream/2077/31615/1/gupea_ 2077_31615_1.pdf

[3] Bullying Harassment in the Workplace, Retrieve from https ://books.google.com.ph/books ?hl=en\&lr=\&id=h8 qYxAhmhUAC\&oi=fnd\&pg=PA 129\&dq=workplace + bullying+thesis +pdf\&ots $=P 3 z z F B \_f y q \&$ sig $=$ cks y WV MXHSdkby8oCDOLJFy fOQ\& redir_esc=y\#v=twopag e\&q=workplace\%20bullying\%20thes is \%20pdf\& $\mathrm{f}=\mathrm{tru}$ $\mathrm{e}$

[4] Namie, Gary (2008). Workplace Bullying Escalated Incivility Retrieve from https://iveybusinessjournal.com/publication/ workplace-bullying-escalated-incivility/

[5] Palmis, Allan (2017). Anti-Bullying Act of 2013. Retrieved from: http://www.manilatimes.net/addressing-workplacebullying/358378/

[6] Ramos, Ryan (2017). Three types of Bullying. Retrieve From http://justpayroll.ph/3-types-office-bullyingphilippines-how-stop-them/

[7] Santos, Sonnie (2014). Workplace Harassment, Retrieve from http://asksonnie.info/ workplaceharassment/

[8] Science for a smarter Workplace (2018), Retrieve from http://www.siop.org/ WhitePapers/default.aspx

[9] Workplace Bullying (2014) Retrieve From http://www.workplacebullying.org/ individuals/problem/definition/

[10] Workplace Bullying: A Review of Its Impact on Businesses, Employees, and the Law, (2015) http://ijbssnet.com/journals/Vol_6_No_2_February_20 15/4.pdf

[11] Workplace Harassment defined, (Occupational Health and Safety Act) Retrieved from: https://www.ontario.ca/page/understand-lawworkplace-violence-and-harassment 